\title{
Response suppression as a function of a vacation from punishment'
}

DAVID ORME-JOHNSON

When $S s$ are removed from a punishing situation for some time and then reintroduced into the same situation, the punishment effect is often increased. The present experiment showed that after a two day vacation the rate of responding of pigeons during punishment was much lower than it was before the vacation. However, with successive vacations, this effect on punishment diminished.

In their recent review of the punishment literature, Azrin \& Holz (1966) discussed the effects of a vacation or time away from punishment on the effectiveness of punishment (p. 398). In these experiments, the parameters of the experiment are kept constant and the response rates during punishment before and after a vacation are compared. A vacation can be defined as either complete removal of the $\mathrm{S}$ from the experimental setting or it can be the removal of only the punishing stimulus while $S$ remains in the experimental setting. Using either procedure, the punished response rate after a vacation is either the same or lower than the pre-vacation response rate (Masserman, 1946; Azrin, 1959a, 1960; Brethower \& Reynolds, 1962). Why would time away from punishment result in a greater punishment effect? One step towards answering this question would be to see how stable the effects of vacation are for repeated measurements using the same vacation interval.

Subjects

The Ss were two white Carneaux pigeons. They were approximately seven years old and were maintained at $78 \% \pm 5 \mathrm{~g}$ of their free feeding weight throughout the investigation.

\section{Apparatus}

The apparatus was a $33 \times 33 \times 33 \mathrm{~cm}$ chamber which was enclosed in a ventilated, sound-attenuated cubicle. Two translucent Gerbrands response keys mounted 23 $\mathrm{cm}$ from the floor and $9 \mathrm{~cm}$ apart were operated by a force of $20 \mathrm{~g}$. The right key was illuminated by a blue light and the left key by a white light. A relay click provided response feedback. Ambient illumination was provided by two $7 \mathrm{~W}$ white lights mounted on the rear ceiling of the chamber. The reinforcer was a $3 \mathrm{sec}$ exposure to a grain mixture of $60 \%$ milo, $50 \%$ vetch, and $10 \%$ hemp.

The punisher shock was $50 \mathrm{msec}$ ac delivered through an $80 \mathrm{~K}$ series resistor. The shock was delivered to the pigeons using the techniques described by Azrin $(1959 \mathrm{~b})$. The resistance for individual Ss varied less than $5 \%$ throughout the experiment and was $1000 \mathrm{ohms}$ for B 2077 and 1400 ohms for B 47.
All programming equipment was located outside the experimental room.

\section{Procedure}

Ss were given one $60 \mathrm{~min}$ session a day seven days per week. Each hourly session consisted of six $10 \mathrm{~min}$ cycles of a multiple schedule. During a cycle, either the right, blue key or the left, white key was illuminated. The schedule of positive reinforcement on both keys was variable interval $1 \mathrm{~min}$ in which the inter-reinforcement time varied randomly from 2 to $120 \mathrm{sec}$ and averaged 60 sec (Ferster \& Skinner, 1957). On the left key, every response was punished with a $50 \mathrm{msec}$ response contingent shock. The shock intensity was initially .2 $\mathrm{mA}$ and was increased in .2 $\mathrm{mA}$ increments. If the response rate during a $10 \mathrm{~min}$ cycle exceeded $90 \%$ of the non-punished rate, the intensity was increased in steps of $.2 \mathrm{~mA}$ until a stable suppression of about $85 \%$ of the non-punished rate was reached. The final shock intensities were $2 \mathrm{~mA}$ for $\mathrm{B} 2077$ and $2.4 \mathrm{~mA}$ for $\mathrm{B} 47$. In addition, between cycles of punishment and non-punishment, there was a 30 sec period during which the key lights and house lights were all inoperative.

Ss' previous experimental history was approximately $100 \mathrm{~h}$ sessions on this multiple schedule, during which they were exposed to a conditioned suppression paradigm. After the last suppression trial, Ss continued to be run seven days a week for three additional weeks on the multiple schedule.

Ss were then shifted to cycles of five days of working and two days of vacation for seven weeks. During a vacation, Ss remained in their home cages and were

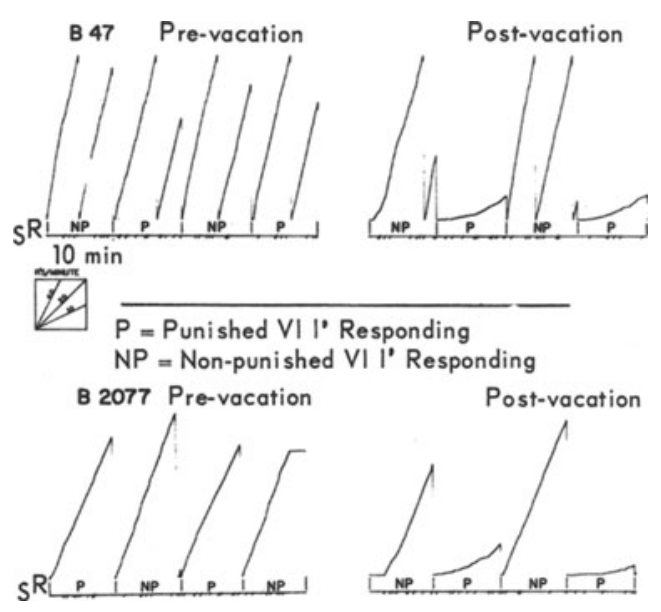

Fig. 1. Cumulative records for before and after a vacation. 


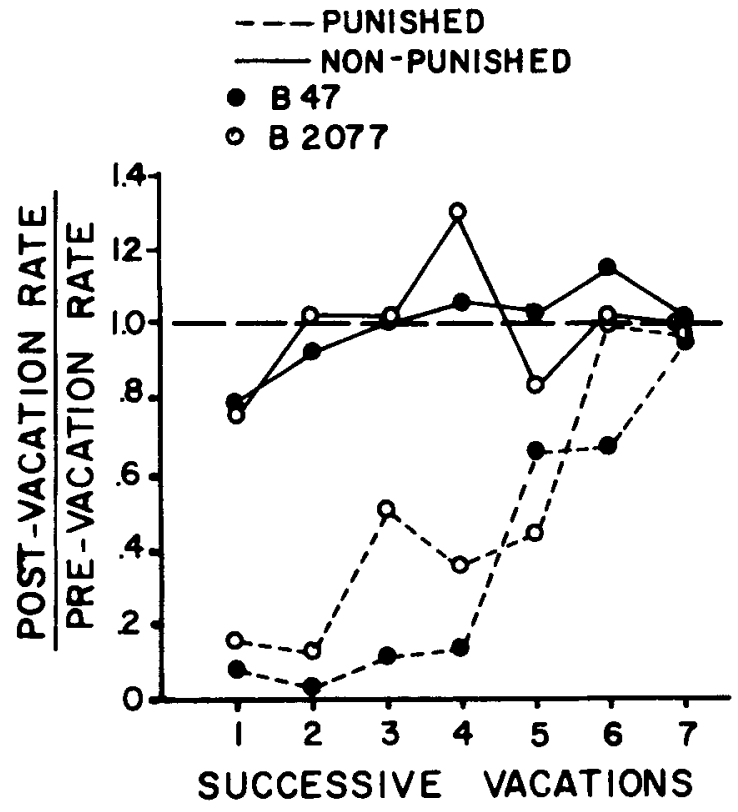

Fig. 2. Response suppression as a function of successive vacations.

given food sufficient to maintain their $78 \%$ weight. Water was available ad lib in the home cage.

\section{Resulis}

Figure 1 shows that the day before the vacation the punished and non-punished response rates were about equal. After the vacation, there was a large decrement in the punished response rate, but little change in the non-punished rate.

However, with successive vacations, a vacation tended to have less and less of an effect on punishment responding. This is shown in Fig 2. In this figure, the response rate for the session before a vacation divided by the response rate for the session after a vacation is plotted on the ordinate against successive vacations plotted on the abscissa. A ratio of 1.0 indicates no change between before and after a vacation, while a small decimal indicates a large decrement after a vacation relative to before the vacation. For both $\mathrm{Ss}$, the two day vacation initially produced a large decrement in the punished response rate, and with successive vacations this decrement decreased until by the seventh replication the vacation had little effect on punished responding. By comparison, the vacation had little effect on the nonpunished component of the multiple schedule.

\section{Discussion}

Experiments in which the independent variable is time away from some constant experimental conditions are often considered in the context of memory and forgetting. However, in the present experiment, the behaviors were well established through months of exposure to the contingencies, so it is unlikely that anything was forgotten. Indeed, the vacation had little effect on VI responding alone. It seems more plausible to consider the vacation as increasing the effectiveness of the punishing stimulus rather than as forgetting of some kind.

But why should time away from punishment increase the effectiveness of punishment? Operationally, the relatively lower punished response rate after a vacation defines the punishing stimulus as more aversive after a vacation. One possible explanation of why a vacation should increase the aversiveness of a punisher is that a behavioral contrast (Reynolds, 1961) develops after the $\mathrm{S}$ is exposed to free feeding during a vacation.

Under the initial arrangement of working seven days a week there was no food given in the home cage. However, during the vacation Ss were fed in the home cage for two days, and the rate drop in punished responding after the vacation may have been a negative contrast effect to the free feeding in the home cage.

There is some evidence (Terrace, 1967) that contrast effects diminish with repeated exposure to the contrast-producing conditions. The present finding that the effects of a vacation on punishment diminish with repeated exposure to vacations is consistent with the view that the vacation effect is a contrast effect.

\section{References}

Azrin, N. H. Punishment and recovery during fixed-ratio performance. J. exp. Anal. Behav., 1959a, 2, 301-305.

Azrin, N. H. A technique for delivering shock to pigeons. J. exp. Anal, Behav., 1959b, 2, 161-163.

Azrin, N. H. Effects of punishment intensity during variableinterval reinforcement. J. exp. Anal. Behav., 1960, 3, 123-142.

Azrin, N. H., \& Holz, W. C. Punishment. In W. K. Honig (Ed.), Operant behavior: Areas of research and application. New York: Appleton-Century-Crofts, 1957.

Brethower, D. M., \& Reynolds, G. S. A facilitative effect of punishment on unpunished behavior. J. exp. Anal. Behav., 1962, 5, 191-199.

Ferster, C. B., \& Skinner, B. F. Schedules of reinforcement. New York: Appleton-Century-Crofts, 1957.

Masserman, J. H. Principles of dynamic psychiatry. Philadelphia: Saunders, 1946.

Reynolds, G. S. Behavioral contrast. J. exp. Anal. Behav., 1961, 4, 57-71.

Terrace, H. S. Behavioral contrast and the peak shift: effects of extended discrimination training. J. exp. Anal. Behav., 1967, $9,613-617$.

\section{Note}

1. This work was supported by Grant NsG 189-61 from the National Aeronautics and Space Administration. 